\title{
PENGATURAN PORTAL PADA PENGURUTAN PARKIR MOBIL DENGAN MENGGUNAKAN RFId DAN PC
}

Oleh:

\author{
Roza Susanti, Budhi Bakhtiar
}

Staf Pengajar Teknik Elektro Politeknik Negeri Padang

\begin{abstract}
The number of vehicles increasing day by day. It will trigger the demand of parking area, especially for car park. To overcome this problem, we offer a solution, by creating a miniatur car parking. This Car park only for members whose can park their car in it. Each car will be equiped by a RFId tag (RFid card) and the RFId sensor (Radio Frequency Identification) which will detecting this card. The main function of the RFid card is to detecting every car come and go from the car parking area. The data are readed from the card need to be checked and verified with the database of member identification (Id) by using Visual Basic 6.0 as the interface. The serial port RS 232 used as the interface to connect RFId sensor and Personal computer. The program in AT89S51 microcontroller will control the motor rotation for opening or closing the parking area gate.
\end{abstract}

Keyword : RFId, tag RFId, Visual Basic 6.0, Personal Computer, RS-232, AT89S51. Microcontroller

\section{PENDAHULUAN}

Pada saat ini perubahan teknologi semakin hari semakin cepat perkembangannya, mengakibatkan juga banyaknya terjadi kekacauan seperti keamanan parkir mobil .

Salah satu contoh adalah meningkat jumlahnya kendaraan, memacu tumbuhnya area parkir yang luas yang mampu menampung banyak kendaraan. Area parkir yang luas ini kemudian menimbulkan masalah dalam hal keamanan, antrian masuk ke parkir, antrian ke luar parkir, menemukan ruang parkir yang kosong. Dan sering juga terjadi pencurian kendaraan yang dilakukan berulang-ulang.
Untuk mengatasi masalah tersebut penulis mencoba menyelesaikan dengan membuat sebuah miniatur tempat parkir mobil untuk pelanggan tetap. Mobil yang masuk dan keluar menggunakan tag (kartu) RFId akan dideteksi oleh sensor RFId (Radio Frequency Identification). Data dari RFId dicocokkan dengan data base identitas pelanggan menggunakan Visual Basic 6.0. Interface yang digunakan sebagai penghubung sensor RFId ke personal computer (PC) adalah port serial RS-232. Data base pada visual basic digunakan sebagai input data pada program mikrokontroller AT89S51 untuk membuka dan menutup portal.

\section{RFId (Radio Frequency}

Identification) adalah proses identifikasi seseorang atau objek 
dengan menggunakan frekuensi transmisi radio. Visual Basic merupakan salah satu bahasa pemrograman visual dan juga salah satu development tools untuk membangun aplikasi daam lingkungan Windows (Kustanto, Imam Budi, 2006). Mikrokontroler AT89S51 adalah low power high

performance CMOS 8 bit, 4 Kbyte flash Programmable and Eresable Read Only Memory (EPROM). Komunikasi RS-232 adalah komunikasi yang dilakukan secara asinkron (asynchronous), yaitu komunikasi serial yang tidak memiliki clock bersama antara pengirim dan penerima (Prasetia, Retna, Catur Edi Widodo, 2004).

\section{Rumusan Masalah}

Berdasarkan latar belakang dapat dirumuskan beberapa permasalahan, antara lain:

1. Bagaimana merancang suatu sistem pengelolaan parkir mobil dengan menggunakan sensor RFId (Radio Frequencyuency

Identification) dan kartu RFId (Tag RFId).

2. Bagaimana membuat data base menggunakan visual basic 6.0.

3. Bagaimana membuat program untuk membuka dan menutup portal menggunakan Mikrokontroller AT89S51.

\section{LANDASAN TEORI}

RFId

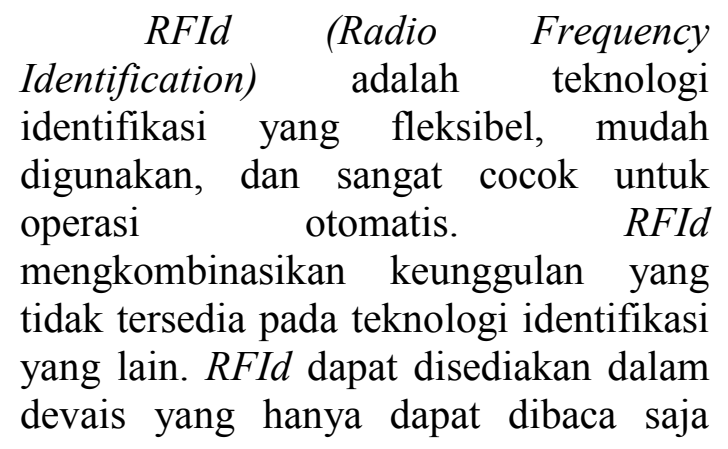

(Read Only) atau dapat dibaca dan ditulis (Read/Write), tidak memerlukan kontak langsung maupun jalur cahaya untuk dapat beroperasi, dapat berfungsi pada berbagai variasi kondisi lingkungan, dan menyediakan tingkat integritas data yang tinggi. Sebagai tambahan, karena teknologi ini sulit untuk dipalsukan, maka RFId dapat menyediakan tingkat keamanan yang tinggi.

Pada sistem RFId umumnya, tag atau transponder ditempelkan pada suatu objek. Setiap tag dapat membawa informasi yang unik, di antaranya: serial number, model, warna, tempat perakitan, dan data lain dari objek tersebut. Ketika tag ini melalui medan yang dihasilkan oleh pembaca RFId yang kompatibel, tag akan mentransmisikan informasi yang ada pada tag kepada pembaca RFId, sehingga proses identifikasi objek dapat dilakukan.

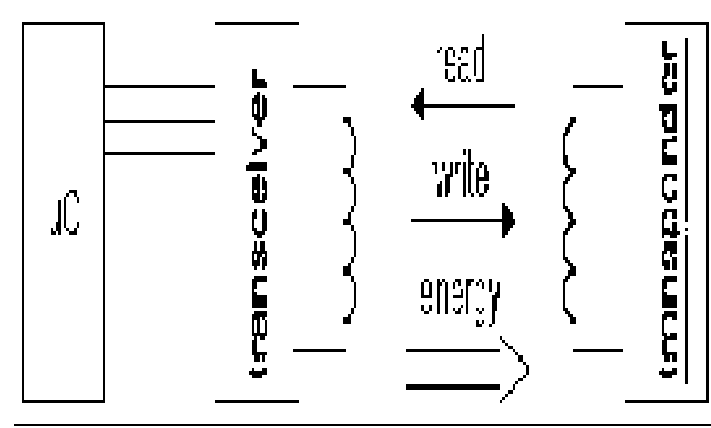

Gambar 1 Kerja sensor

Sistem RFId terdiri dari empat komponen, di antaranya seperti dapat dilihat pada gambar 1 .

1. Tag, Ini adalah devais yang menyimpan informasi untuk identifikasi objek. Tag RFId sering juga disebut sebagai transponder.

2. Antena untukmenstransmisi menstransmisikan sinyal frekuensi radio antara pembaca RFId dengan tag FRId. 
3. RFId Reader : adalah perangkat yang kompatibel dengan tag RFId yang akan berkomunikasi secara wireless dengan tag.

4. Software Aplikasi: adalah aplikasi pada sebuah workstation atau PC yang dapat membaca data dari tag melalui pembaca RFId. Baik tag dan pembaca RFId diperlengkapi dengan antena sehingga dapat menerima dan memancarkan elektromagnetik



Gambar 2. Sistem RFID

\section{Tag RFID}

Tag RFID adalah perangkat yang dibuat dari rangkaian elektronika dan antena yang terintegrasi di dalam rangkaian tersebut. Ada dua tag yang beredar dipasaran yaitu, passive tag dan $\mathrm{read} /$ write tag. Pada passive tag, data ID tersebut merupakan data bawaan dari pabrik sehingga tidak dapat dirubah. Sedangkan pada read/write tag, data IDnya dapat diubah sesuai kemauan pengguna. Hal ini berlaku juga untuk sensor RFID, ada sensor yang dapat membaca ID dari tag, dan ada pula sensor yang dapat membaca dan menulis tag dengan data ID.

Rangkaian elektronik dari tag RFID umumnya memiliki memori sehingga tag ini mempunyai kemampuan untuk menyimpan data. Memori pada tag secara dibagi menjadi sel-sel. Beberapa sel menyimpan data Read Only, misalnya serial number yang unik yang disimpan pada saat tag tersebut diproduksi. Selain pada RFID mungkin juga dapat ditulis dan dibaca secara berulang.

Sebuah tag RFID atau transponder, terdiri atas sebuah mikro (microchip) dan sebuah sistem ( Gambar 3 ) . Chip mikro itu sendiri dapat berukuran sekecil butiran pasir, seukuran $0.4 \mathrm{~mm}$. Chip tersebut menyimpan nomor seri yang unik atau informasi lainnya tergantung kepada tipe memorinya. Tipe memori itu sendiri dapat read-only, read-write, atau writeonceread-many. Antena yang terpasang pada chip mikro mengirimkan informasi dari chip ke reader. Biasanya rentang pembacaan diindikasikan dengan besarnya sistem. Antena yang lebih besar mengindikasikan rentang pembacaan yang lebih jauh. Tag tersebut terpasang atau tertanam dalam obyek yang akan diidentifikasi. Tag dapat discan dengan reader bergerak maupun stasioner menggunakan gelombang radio. 


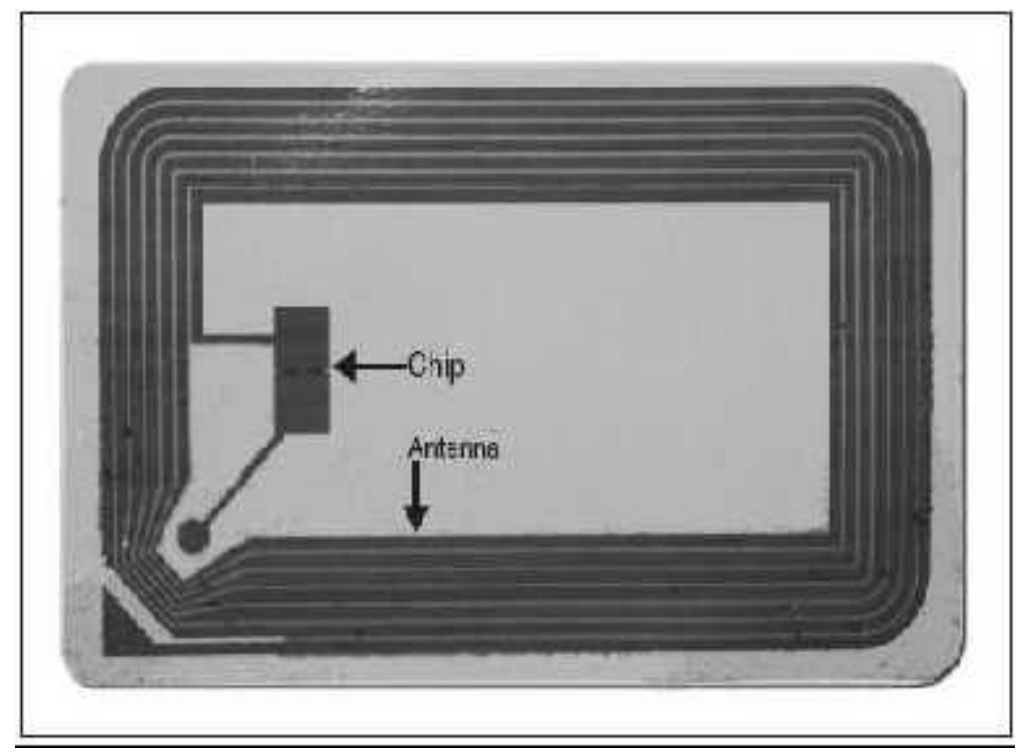

Gambar 3. Tag RFId

Tag versi paling sederhana adalah tag pasif, yaitu tag yang tidak memiliki catu daya sendiri serta tidak dapat menginisiasi komunikasi dengan reader. Sebagai gantinya, tag merespon emisi frekuensi radio dan menurunkan dayanya dari gelombang energi yang dipancarkan oleh reader. Sebuah tag pasif minimum mengandung sebuah indentifier unik dari sebuah item yang dipasangi tag tersebut. Data tambahan dimungkinkan untuk ditambahkan pada tag, tergantung kepada kapasitas penyimpanannya.

Dalam keadaan yang sempurna, sebuah tag dapat dibaca dari jarak sekitar 10 hingga 20 kaki. Tag pasif dapat beroperasi pada frekuensi rendah (low frequencyuency, $L F$ ), frekuensi tinggi (high frequencyuency, $H F$ ), frekuensi ultra tinggi (ultrahigh frequencyuency, UHF), atau gelombang mikro (microwave).

Tag semi pasif adalah versi tag yang memiliki catu daya sendiri (baterai) tetapi tidak dapat menginisiasi komunikasi dengan reader. Dalam hal ini baterai digunakan oleh tag sebagai catu daya untuk melakukan fungsi yang lain seperti pemantauan keadaan lingkungan dan mencatu bagian elektronik internal tag, serta untuk memfasilitasi penyimpanan informasi. Tag versi ini tidak secara aktif memancarkan sinyal ke reader. Sebagian tag semi pasif tetap dominan hingga menerima sinyal dari reader.
Tag semi pasif dapat dihubungkan dengan sensor untuk menyimpan informasi untuk peralatan keamanan Sistem. Tag aktif adalah tag yang selain memiliki sistem dan chip juga memiliku catu daya dan pemancar serta mengirimkan sinyak kontinyu. Tag versi ini biasanya memiliki kemampuan baca tulis, dalam hal ini data tag dapat ditulis ulang atau dimodifikasi. Tag aktif dapat menginisiasi komunikasi dan dapat berkomunikasi pada jarak yang lebih jauh, hingga 750 kaki, tergantung kepada daya baterainya.

Pada tag dengan tipe memori read / write, data dapat dimutakhirkan jika diperlukan. Sebagai konsekuensinya kapasitas memorinya lebih besar dibandingkan tag read-only. Tag seperi ini biasanya digunakan ketika data yang tersimpan di dalamnya perlu pemutakhiran seiring dengan daur hidup produk, misalnya di pabrik. Tag dengan tipe memori writeonce read-many memungkinkan informasi disimpan sekali, tetapi tidak membolehkan perubahan berikutnya terhadap data. Tag tipe ini memiliki fitur keamanan read-only dengan menambahkan fungsionalitas tambahan dari tag read/write.

Berdasarkan catu daya tag, tag RFID dapat digolongkan menjadi :

1. Tag Aktif: yaitu tag yang catu dayanya diperoleh dari baterai, sehingga akan mengurangi daya 
yang diperlukan oleh pembaca RFID dan tag dapat mengirimkan informasi dalam jarak yang lebih jauh. Kelemahan dari tipe tag ini adalah harganya yang mahal dan ukurannya yang lebih besar karena lebih komplek. Semakin banyak fungsi yang dapat dilakukan oleh tag RFID maka rangkaiannya akan semakin komplek dan ukurannya akan semakin besar.

2. Tag Pasif: yaitu tag yang catu dayanya diperoleh dari medan yang dihasilkan oleh pembaca RFID. Rangkaiannya lebih sederhana, harganya jauh lebih murah, ukurannya kecil, dan lebih ringan. Kelemahannya adalah tag hanya dapat mengirimkan informasi dalam jarak yang dekat dan pembaca RFID harus menyediakan daya tambahan untuk tag RFID. Tag RFID telah sering dipertimbangkan untuk digunakan sebagai barcode pada masa yang akan datang. Pembacaan informasi pada tag RFID tidak memerlukan kontak sama sekali. Karena kemampuan rangkaian terintegrasi yang modern, maka tag RFID dapat menyimpan jauh lebih banyak informasi dibandingkan dengan barcode.

\section{Reader RFID Atau Pembaca RFID}

Untuk berfungsinya sistem RFID diperlukan sebuah reader atau alat scanning device yang dapat membaca tag dengan benar dan mengkomunikasikan hasilnya ke suatu basis data (WWW. Emmicroelectronic.Com. RFID).

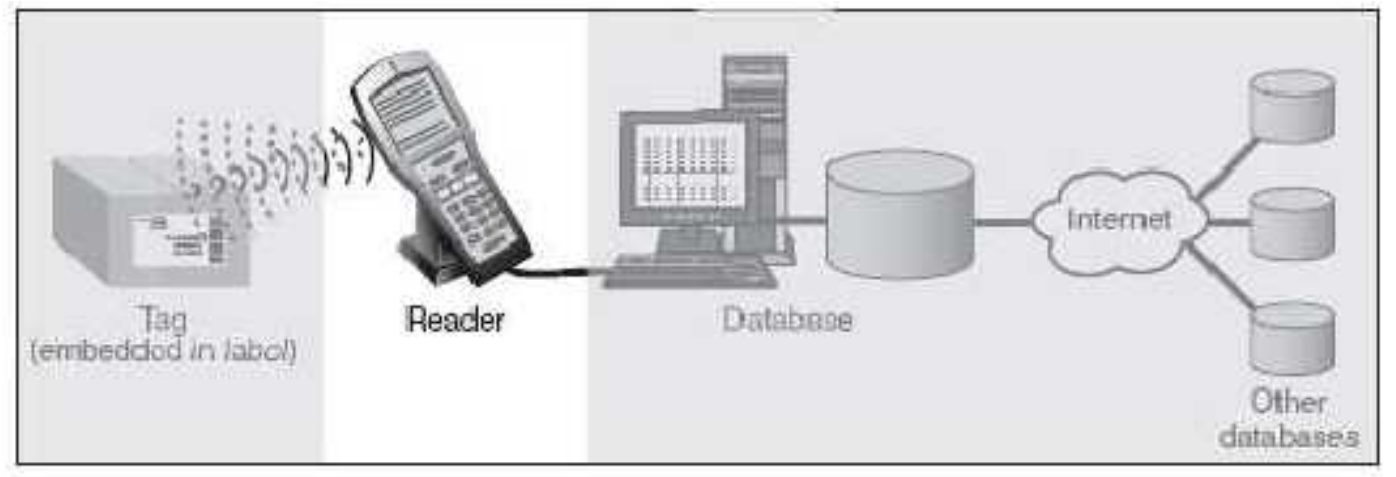

Gambar 4. Reader RFId

Sebuah reader menggunakan antenanya sendiri untuk berkomunikasi dengan tag. Ketika reader memancarkan gelombang radio, seluruh tag yang dirancang pada frekuensi tersebut serta berada pada rentang bacanya akan memberikan respon. Sebuah reader juga dapat berkomunikasi dengan tag tanpa line of sight langsung, tergantung kepada frekuensi radio dan tipe tag ( aktif, pasif atau semipasif ) yang digunakan. Reader dapat memproses banyak item sekaligus. Menurut bentuknya, reader dapat berupa reader bergerak seperti peralatan genggam, atau stasioner seperti peralatan point-of-sale di supermarket. Reader dibedakan berdasarkan kapasitas penyimpanannya, kemampuan pemrosesannya, serta frekuensi yang dapat dibacanya.

Basis data merupakan sebuah sistem informasi sistem pada posisi back-end yang bekerja melacak dan menyimpan informasi tentang item bertag. Informasi yang tersimpan dalam basis data dapat terdiri dari identifier item, deskripsi, pembuat, pergerakan dan lokasinya. Tipe informasi yang disimpan dalam basis data dapat bervariasi tergantung kepada aplikasinya. Sebagai contoh, data yang disimpan pada sistem pembayaran tol akan berbeda dengan yang disimpan pada rantai supply. Basis data juga dapat dihubungkan dengan jaringan lainnya seperti local area network (LAN) yang dapat 
menghubungkan basis data ke Internet. Konektivitas seperti ini memungkinkan sharing data tidak hanya pada lingkup basis data sistem.
Sebuah pembaca RFId harus menyelesaikan dua buah tugas, yaitu:

1. Menerima perintah dari software aplikasi

2. Berkomunikasi dengan tag RFId

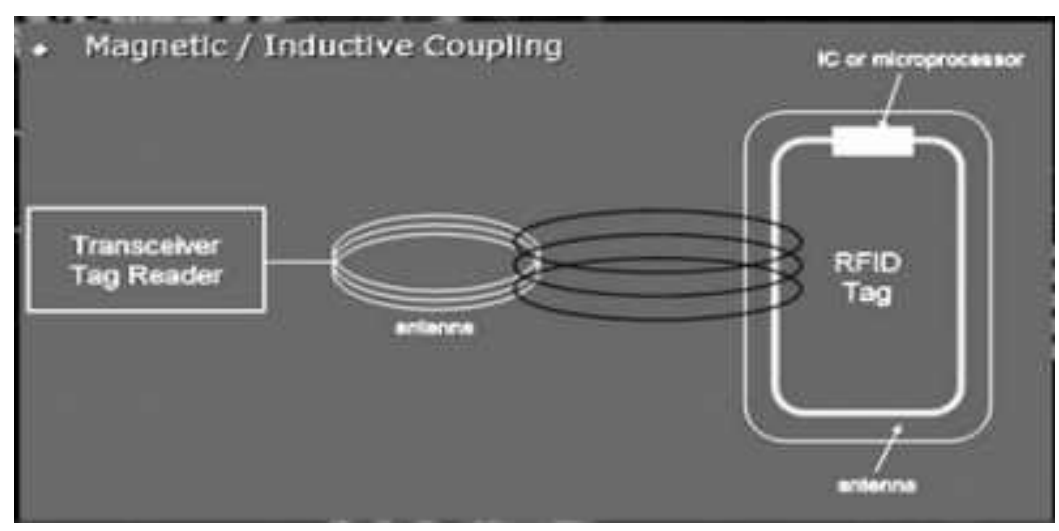

Gambar 5 Metode Pengiriman data RFID pasif ke piranti pembaca



Gambar 6 Metode pengiriman data RFID pasif ke piranti pembaca

Metode pengiriman data kartu $R F I D$ pasif ke piranti pembaca dapat dibagi menjadi 2 macam, yaitu:

1. Inductive Coupling

Gulungan tembaga pada piranti pembaca membangkitkan medan elektromagnetik, kemudian gulungan yang ada di kartu RFID terinduksi oleh medan ini, hasil induksi inilah yang menjadi sumber tenaga bagi kartu RFID untuk mengirimkan kembali sinyal yang berisi data ke piranti pembaca. Karena menggunakan prinsip induksi ini, maka jarak antara kartu RFID dengan piranti pembaca juga harus pendek agar induksi dapat ditangkap. Inductive coupling ini digunakan pada kartu RFID dengan low frequency dan high frequency.

\section{Propagation Coupling}

Pada Sistem ini, energi yang digunakan berasal dari energi elektromagnetik (gelombang radio ) yang dipancarkan oleh piranti pembaca. Kartu RFID kemudian akan mengumpulkan energi elektromagnetik ini untuk digunakan sebagai sumber daya mengirimkan data yang dimilikinya ke piranti pembaca. Mekanisme ini disebut 
dengan backscatter. Modulasi bit data ke frekuensi menggunakan amplitude shift keying, phase shift keying, atau frequency shift keying.

Pembaca RFID adalah merupakan penghubung antara software aplikasi dengan antena yang akan meradiasikan gelombang radio ke tag RFID. Gelombang radio yang diemisikan oleh antena berpropagasi pada ruangan di sekitarnya. Akibatnya data dapat berpindah secara wireless ke tag RFID yang berada berdekatan dengan antenna (WWW. Emmicroelectronic.Com. RFID).

\section{Blok Diagram Sistem}

Sebelum perancangan sistem dilakukan, terlebih dahulu menggunakan blok diagram sebagai langkah awal pembuatan sistem. Di mana blok diagram ini menggambarkan secara umum bagaimana sistem kerja rangkaian secara keseluruhan

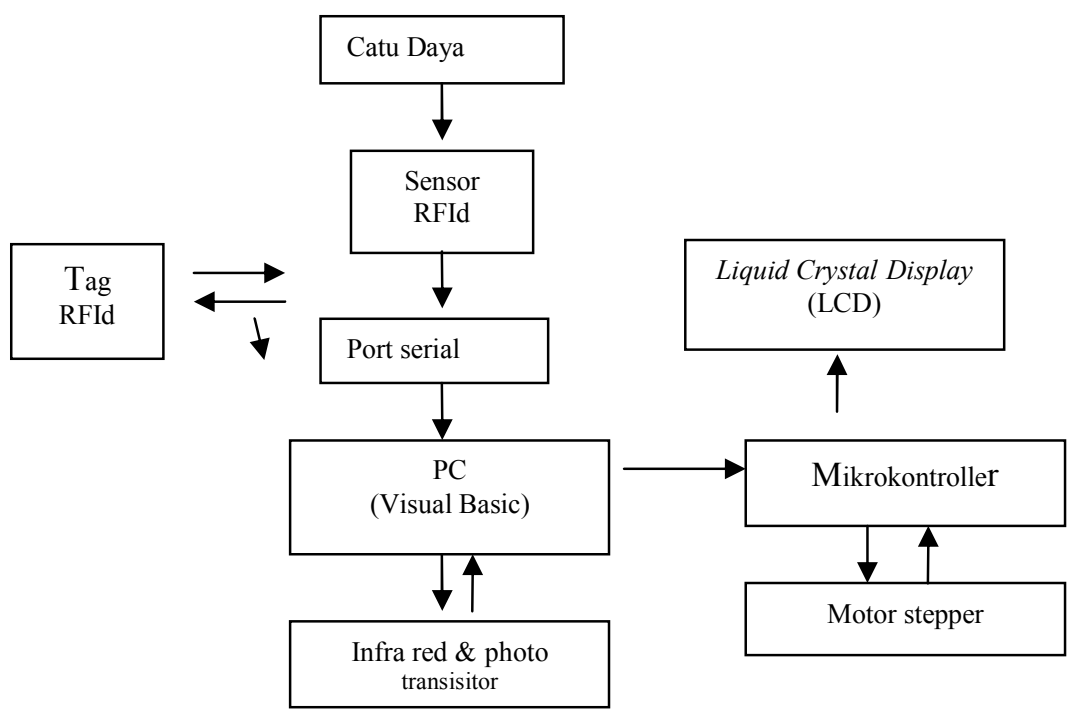

Gambar 7 Blok diagram sistem Pengelolaan Parkir

Listing program mikrokontroller AT89S51 untuk membuka portal (Ramon Zamora, dkk. 2005) adalah sebagai berikut:

\begin{tabular}{|c|c|c|}
\hline \\
\hline \multirow{2}{*}{\multicolumn{3}{|c|}{$\begin{array}{l}\text { \$MOD52 } \\
\text { ORG 100H } \\
\text { MULAI: }\end{array}$}} \\
\hline & & \\
\hline & MOV & $\mathrm{P} 0, \# 0 \mathrm{H}$ \\
\hline & CALL & M1_KIRI \\
\hline & MOV & $\mathrm{R} 2, \overline{\# 2}$ \\
\hline & CALL & DELAY1 \\
\hline & CALL & M2_KIRI \\
\hline & MOV & $\mathrm{R} 2, \overline{\#} 2$ \\
\hline & CALL & DELAY1 \\
\hline & CALL & M1_KANAI \\
\hline & MOV & R2, \#2 \\
\hline & CALL & DELAY1 \\
\hline & CALL & M2_KANA \\
\hline & MOV & $\mathrm{R} 2, \overline{\#} 2$ \\
\hline
\end{tabular}

CALL DELAY 1

JMP MULAI



M1 KIRI:

RET

MOTOR 1 PUTAR KANAN 


$\begin{aligned} & \text { M1_KANAN: } \\ & \text { MOV } \text { P0,\#08H } \\ & \text { CALL } \text { DELAY } \\ & \text { MOV } \text { P0,\#04H } \\ & \text { CALL } \text { DELAY } \\ & \text { MOV } \text { P0,\#02H } \\ & \text { CALL } \text { DELAY } \\ & \text { MOV } \text { P0,\#01H } \\ & \text { CALL } \text { DELAY } \\ & \text { JB } \\ & \text { P3.0,M1_KANAN } \\ & \text { MOV } \text { P0,\#0H } \\ & \text { RET }\end{aligned}$

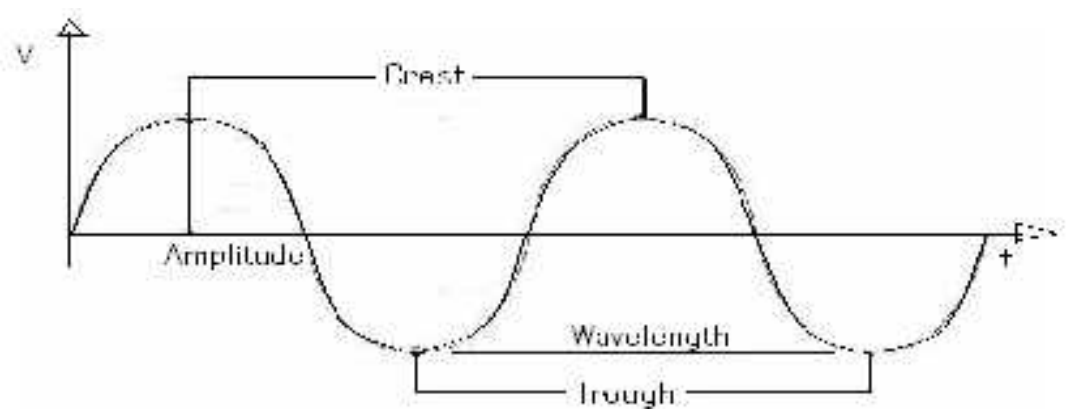

Gambar 8. Frekuensi RFId

\section{Pengujian range RFID}

dilakukan Jen mengunak rangkaian yang sudah ada. Pendeteksian tag oleh sensor RFID akan ditandai dengan menyalanya lampu led berwarna hijau.
Dari gambar 8 di atas ditemukan istilah Crest, Amplitude, Wavelength dan Trough. Crest adalah titik tertinggi dari gelombang sedangkan Trough adalah titik terendah dari gelombang. Amplitude adalah tinggi dari sebuah puncak atau dalam dari sebuah lembah, Wavelength adalah panjang gelombang atau jarak antara dua puncak dan dua lembah.

Frekuensi RFId seperti gambar 3.3 dihasilkan ketika tag RFId dideteksi oleh sensor RFId. Bentuk gelombang seperti ini dapat dikategorikan gelombang elektromagnetik. Gelombang elektromagnet adalah gelombang transversal sebab gangguannya berupa medan magnetic dan medan listrik yang saling tegak lurus dan keduanya tegak lurus arah rambat gelombang (www.emmicroelectronic.com)
Pada saat pengujian apabila tag didekatkan pada reader maka reader akan mendeteksi identitas dari tag. Pada saat identitas dari tag didapat, sensor akan mengirimkan data ke mikrokontroler. Pada saat yang bersamaan dengan pengiriman, pin 8 akan memberikan logika ' 1 ', sehingga led akan menyala.

Untuk pengujian ini digunakan 7 buah tag. Pengujian dilakukan dengan cara mengukur jarak minimal yang dibutuhkan sensor agar led dapat menyala. Pada reader diletakkan sebuah penggaris. Tag akan didekatkan secara perlahan. Pada saat led menyala, maka akan didapat jarak minimal yang dibutuhkan agar reader dapat membaca tag. Pendekatan dilakukan dengan posisi berbeda - beda. Sebelum itu akan dikenalkan tag dan sensor yang dipakai. 


\section{Pengujian Tag RFID}

Pengujian tag RFID dilakukan dengan berbagai macam percobaan seperti jarak, posisi dan penghalang terhadap sensor RFID ( reader RFID ). Hal tersebut akan dibahas pada subbab berikut.

\section{Pengujian Tag RFID dengan jarak dan posisi tag terhadap sensor RFID}

Pengujian tag RFID dengan jarak dan posisi tag terhadap sensor RFID dibagi menjadi 3 tahap yaitu :

1. Pengujian tag RFID dengan jarak dan posisi sejajar terhadap sensor RFID

Proses pengukurannya dilakukan seperti gambar 9.

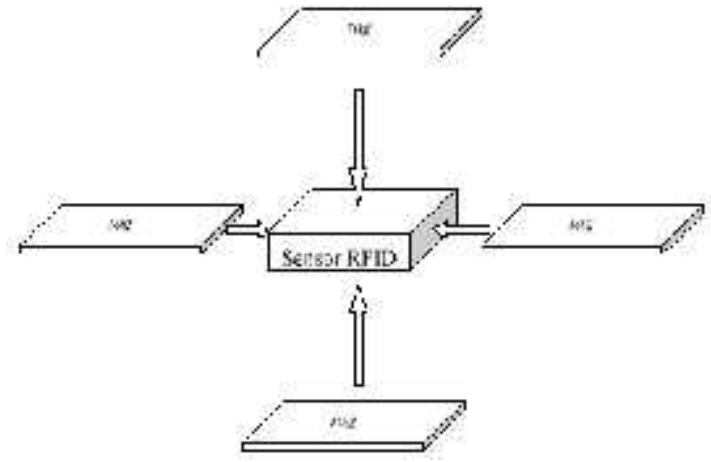

Gambar 9 Pengujian dengan posisi tag sejajar sensor RFI

Tabel 1. Hasil pengukuran posisi tag sejajar dengan sensor RFID

\begin{tabular}{cccccc}
\hline $\begin{array}{c}\text { No. } \\
\text { Kartu }\end{array}$ & $\begin{array}{c}\text { Posisi } \\
\text { atas } \\
(\mathbf{c m})\end{array}$ & $\begin{array}{c}\text { Posisi } \\
\text { bawah } \\
(\mathbf{c m})\end{array}$ & $\begin{array}{c}\text { Posisi } \\
\text { kiri }(\mathbf{c m})\end{array}$ & $\begin{array}{c}\text { Posisi } \\
\text { kanan } \\
(\mathbf{c m})\end{array}$ & Hasil \\
\hline $\mathbf{0 2 1 3 6 8 2 1}$ & 5 & 4 & 1 & 1,5 & Terdeteksi \\
& 5.5 & 4.5 & 1.5 & 2 & Tidak terdeteksi \\
$\mathbf{0 2 1 3 6 8 2 3}$ & 5.5 & 4.5 & 1.5 & 1.5 & Terdeteksi \\
& 6 & 5 & 1.5 & 2 & Tidak terdeteksi \\
$\mathbf{0 2 1 3 7 6 8 2}$ & 6 & 4 & 1.5 & 1.5 & Terdeteksi \\
& 6.5 & 4.5 & 2 & 2 & Tidak terdeteksi \\
$\mathbf{0 2 1 3 9 5 6 1}$ & 3 & 3 & 2 & 1 & Terdeteksi \\
& 3.5 & 3.5 & 2.5 & 1.5 & Tidak terdeteksi \\
$\mathbf{1 4 9 5 8 7 7 5}$ & 4 & 3 & 1.5 & 1 & Terdeteksi \\
& 4.5 & 3.5 & 2 & 1.5 & Tidak terdeteksi \\
$\mathbf{1 4 8 4 9 4 3 3}$ & 3 & 4 & 2 & 1 & Terdeteksi \\
& 3.5 & 4.5 & 2.5 & 1.5 & Tidak terdeteksi \\
$\mathbf{1 7 9 2 1 7 2 4}$ & 5 & 3 & 1 & 1 & Terdeteksi \\
& 5.5 & 3.5 & 1.5 & 1.5 & Tidak terdeteksi \\
& & & & & \\
\hline
\end{tabular}

Dari tabel 1 dapat dilihat bahwa . jarak terjauh yang dapat dideteksi oleh sensor adalah sejauh $6 \mathrm{~cm}$. Jarak terjauh tersebut dicapai oleh tag dengan posisi sejajar oleh sensor RFID dan didekatkan dari atas sensor

2. Pengujian tag RFID dengan jarak dan posisi tegak lurus terhadap sensor RFID. Proses pengukuran dilakukan seperti gambar 10 . 


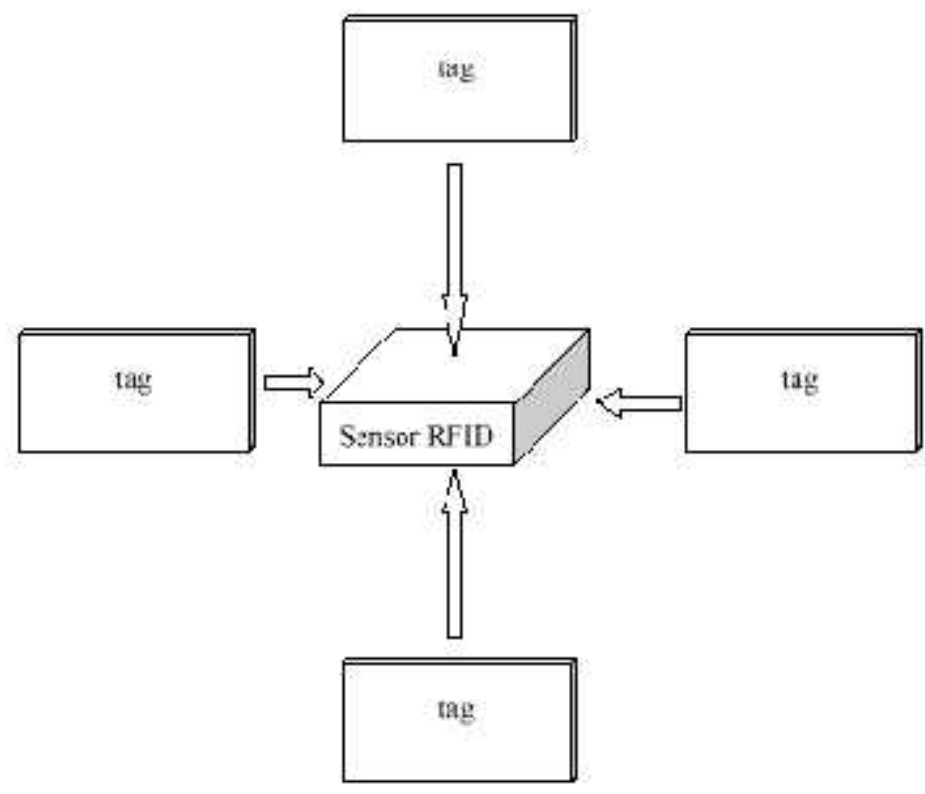

Gambar 10. Pengujian dengan posisi tag tegak lurus dengan sensor RFI

Tabel 2. Hasil pengukuran posisi tag tegak lurus dengan sensor RFID

\begin{tabular}{cccccc}
\hline $\begin{array}{c}\text { No. } \\
\text { Kartu }\end{array}$ & $\begin{array}{c}\text { Posisi } \\
\text { atas } \\
(\mathbf{c m})\end{array}$ & $\begin{array}{c}\text { Posisi } \\
\text { bawah } \\
(\mathbf{c m})\end{array}$ & $\begin{array}{c}\text { Posisi } \\
\text { kiri } \\
(\mathbf{c m})\end{array}$ & $\begin{array}{c}\text { Posisi } \\
\text { kanan } \\
(\mathbf{c m})\end{array}$ & Hasil \\
\hline $\mathbf{0 2 1 3 6 8 2 1}$ & 1,5 & 1 & 1 & 1 & Terdeteksi \\
& 2 & 1,5 & 1,5 & 1,5 & Tidak terdeteksi \\
$\mathbf{0 2 1 3 6 8 2 3}$ & 1 & 0,5 & 0,5 & 0,5 & Terdeteksi \\
& 1,5 & 1 & 1 & 1 & Tidak terdeteksi \\
$\mathbf{0 2 1 3 7 6 8 2}$ & 1,5 & 1 & 1 & 1 & Terdeteksi \\
& 1 & 1,5 & 1,5 & 1,5 & Tidak terdeteksi \\
$\mathbf{0 2 1 3 9 5 6 1}$ & 1 & 0,5 & 0,5 & 1 & Terdeteksi \\
& 1,5 & 1 & 1 & 1,5 & Tidak terdeteksi \\
$\mathbf{1 4 9 5 8 7 7 5}$ & 3 & 2,5 & 2 & 2 & Terdeteksi \\
& 3,5 & 3 & 2,5 & 2,5 & Tidak terdeteksi \\
$\mathbf{1 4 8 4 9 4 3 3}$ & 2 & 1 & 1.5 & 1.5 & Terdeteksi \\
& 2.5 & 1.5 & 2 & 2 & Tidak terdeteksi \\
$\mathbf{1 7 9 2 1 7 2 4}$ & 3 & 2.5 & 1 & 1 & Terdeteksi \\
& 3.5 & 3 & 1.5 & 1.5 & Tidak terdeteksi \\
\hline
\end{tabular}

\section{KESIMPULAN}

1. RFId adalah sistem untuk pengenalan objek dengan menggunakan frekuensi radio. Frekuensi yang digunakan pada RFID ini adalah low frequency dan kemampuan
2. pengiriman sinyalnya termasuk dalam sistim RFID pasif.

3. RFID reader ini dapat mendeteksi walaupun terhalang benda lain kecuali benda yang terbuat dari bahan logam. 
4. Data tag yang tersimpan pada database digunakan sebagai input mikrokontroller untuk membuka atau menutup portal. Jika data tidak tersimpan maka portal tidak akan terbuka.

\section{UCAPAN TERIMA KASIH}

Penulis mengucapkan terima kasih kepada Rafki Budiman alumni Politeknik Negeri Padang 2009, dimana telah bekerjasama menyelesaikan penulisan jurnal ini baik dalam

\section{DAFTAR PUSTAKA}

http://agfi.staff.ugm.ac.id

http://www. geekhideout.com/iodll.shtm

Kustanto, Imam Budi. 2006. Tutorial Visual Basic 6.0 Membuat Program Logistik Barang. (WWW. IlmuKomputer.Com)

Prasetia, Retna, Catur Edi Widodo, 2004. .Interfacing Port Paralel dan Port Serial Dengan Visual Basic 6.0, ANDI, Yogyakarta.

Tooley, Mike. Rangkaian Elektronik, prinsip dan aplikasi.

Ramon Zamora, dkk. 2005. Sistem Pengendalian Motor Stepper tanpa kabel Berbasis Mikrokontroler at89c51. Jakarta.

WWW. Emmicroelectronic.Com. RFID Made Easy. 2002.

WWW.jonsanet.cjb.net

WWW.Petra.ac.id

WWW.proyek_akhir.tk 
ISSN : 2085-6989

\section{HALAMAN INI SENGAJA DIKOSONGKAN}

